SPE3 Far--field Quicklook

R. J. Mellors, S. Myers, S. Ford, W. R. Walter, T. Hauk, S. Ruppert, A. Pitarka

October 1, 2012 
This document was prepared as an account of work sponsored by an agency of the United States government. Neither the United States government nor Lawrence Livermore National Security, LLC, nor any of their employees makes any warranty, expressed or implied, or assumes any legal liability or responsibility for the accuracy, completeness, or usefulness of any information, apparatus, product, or process disclosed, or represents that its use would not infringe privately owned rights. Reference herein to any specific commercial product, process, or service by trade name, trademark, manufacturer, or otherwise does not necessarily constitute or imply its endorsement, recommendation, or favoring by the United States government or Lawrence Livermore National Security, LLC. The views and opinions of authors expressed herein do not necessarily state or reflect those of the United States government or Lawrence Livermore National Security, LLC, and shall not be used for advertising or product endorsement purposes.

This work performed under the auspices of the U.S. Department of Energy by Lawrence Livermore National Laboratory under Contract DE-AC52-07NA27344. 


\section{SPE3 Far-field Quicklook}

R. J. Mellors, S. Myers, S. Ford, W. R. Walter, T. Hauk, S. Ruppert, A. Pitarka

\section{LLNL-TR-586676}

Introduction. The purpose of this report is to provide an overview of the seismic data collected during the SPE3 chemical shot. Farfield seismic data includes data collected at distances of more than $100 \mathrm{~m}$ from the shot and instruments deployed for the experiments. This report does not address infrasound, remote sensing, or seismic data collected by regional permanent stations. The primary goal is a fast data check before extensive analysis.

The SPE3 shot was conducted on July 24, 2012 (DOY 206) at the SPE test site and in the same borehole as SPE1 and SPE2 (table 1). Data processing at LLNL primarily used mini-seed data volumes downloaded from the UNR server along with associated metadata. This is in contrast to earlier shots, where LLNL data was based on reformatted Reftek data.

Sensor deployment was similar to previous shots, with a few changes. Parts of lines $1(13,14,15,16), 3(23,26,36)$, and $5(1-12)$ were recorded by telemetry as well as to disk, which provided immediate access to the data. A small array (6 station) geophone array was deployed southeast of the shot near AF9 to measure particle motions. A new rotational sensor (ATA ARS-16) was deployed at station L3-20.

Table 1. SPE shot parameters

\begin{tabular}{|l|l|l|l|l|l|l|}
\hline & TNT eq & SHANFO & $\begin{array}{l}\text { Depth } \\
(\boldsymbol{m})\end{array}$ & $\begin{array}{l}\text { Date/Time } \\
(\mathbf{G M T})\end{array}$ & & \\
\hline SPE1 & $100($ nom.) & 220.92 & 55 & $05 / 03 / 11$ & $22: 00: 00.011$ & $2011: 123$ \\
\hline SPE2 & 992 & 2571.96 & 45 & $10 / 25 / 11$ & $19: 00: 00.012$ & $2011: 298$ \\
\hline SPE3 & 899 & 2332.76 & 45 & $07 / 24 / 12$ & $18: 00: 00.448$ & $2012: 206$ \\
\hline
\end{tabular}


Timing and location. Timing and location appear good for all stations with no obvious gross errors (> 10 samples relative shift). Detailed measurements of $\mathrm{P}$ arrival time suggest a possible shift with respect to SPE2 of approximately 2 milliseconds at the geophone stations (500 $\mathrm{Hz}$ sample rate), with larger shifts at stations recorded on telemetry $(250 \mathrm{~Hz}$ sample rate) [Patton et al., 2012]. Investigations are under way to estimate the reliability of the signal timing at this level, both at the Reftek digitizer and during subsequent data reformatting.

Orientation, polarity, and gain. L4-04 incorrect polarity? Gains on episensors on L5-10 and L1-10 appear high. L2-20 Guralp appear anomalous.

Gains on rotational sensor vary greatly.

\section{Conclusions and recommendations.}

- The data distribution system worked well and investigators had access to data quickly after the shot.

- Verify timing at the sample-rate level for Reftek timing and data reformatting.

- Additional QC before shots to eliminate all errors and inconsistencies in gain setting.

- Develop plan for adjusting sample rates and recording data well beforehand to allow adequate preparation for data changes in the field or on telemetry.

Data summary comments. A series of figures (\#2-9) have been prepared which display the data for each line and sensor type. Scaling is proportional to distance, which preserves anomalies. Red indicates possible problems. 
Figures 10-14 show both SPE2 and SPE3 (red) data for comparison. In general, the waveforms are extremely similar in amplitude and in timing, although a possible delay is visible in Figure 10. As mentioned earlier, this is being investigated.

\section{Comments:}

\section{Line 1}

L1-17.CLZ, L1-18.CLZ, and L1-19.CLZ are very low amplitude with high noise; no moveout?

\section{Line 2}

L2-01.CLZ - low amplitude; same moveout as L2-02 (crosstalk?) [high noise]

L2-03.CLZ - low amplitude [high noise]

L2-12.CLR - low amplitude with respect to L2-12.CLZ and CLT

L2-13.CLZ, L2-14.CLZ - low amplitude, [high noise]

L2-10.CN* [all channels on episensor]

\section{Line 3}

L3-03.CLZ - low amplitude, [high noise] cross-talk?

L3-20.DHR - severe problem [high-frequency sinusoid]

L3-28.CLZ (Trillium) - no signal, noise only

\section{Line 4}

L4-07.CLZ - low amplitude, incorrect moveout, high noise [cross-talk?]

\section{Line 5}

L5-09.CLZ - low amplitude [high noise]

L5-10.CLZ - low amplitude [high noise]

L5-12.CLZ - no signal noise

L5-24.CHE - no signal

L5-26.CHN - no signal

L5-28.CHE - no signal

\section{Small array}

Responses (or possibly site) for center element appear anomalous (Figure 15).

\section{Amplitudes}

Some stations (e.g. L2-02) showed slightly anomalous amplitudes with respect to expected amplitudes based on empirical relationships. Examination of pre-event noise suggests that this may be due to the sensor. This is being further examined. 


\section{SPE3 L1 CL}

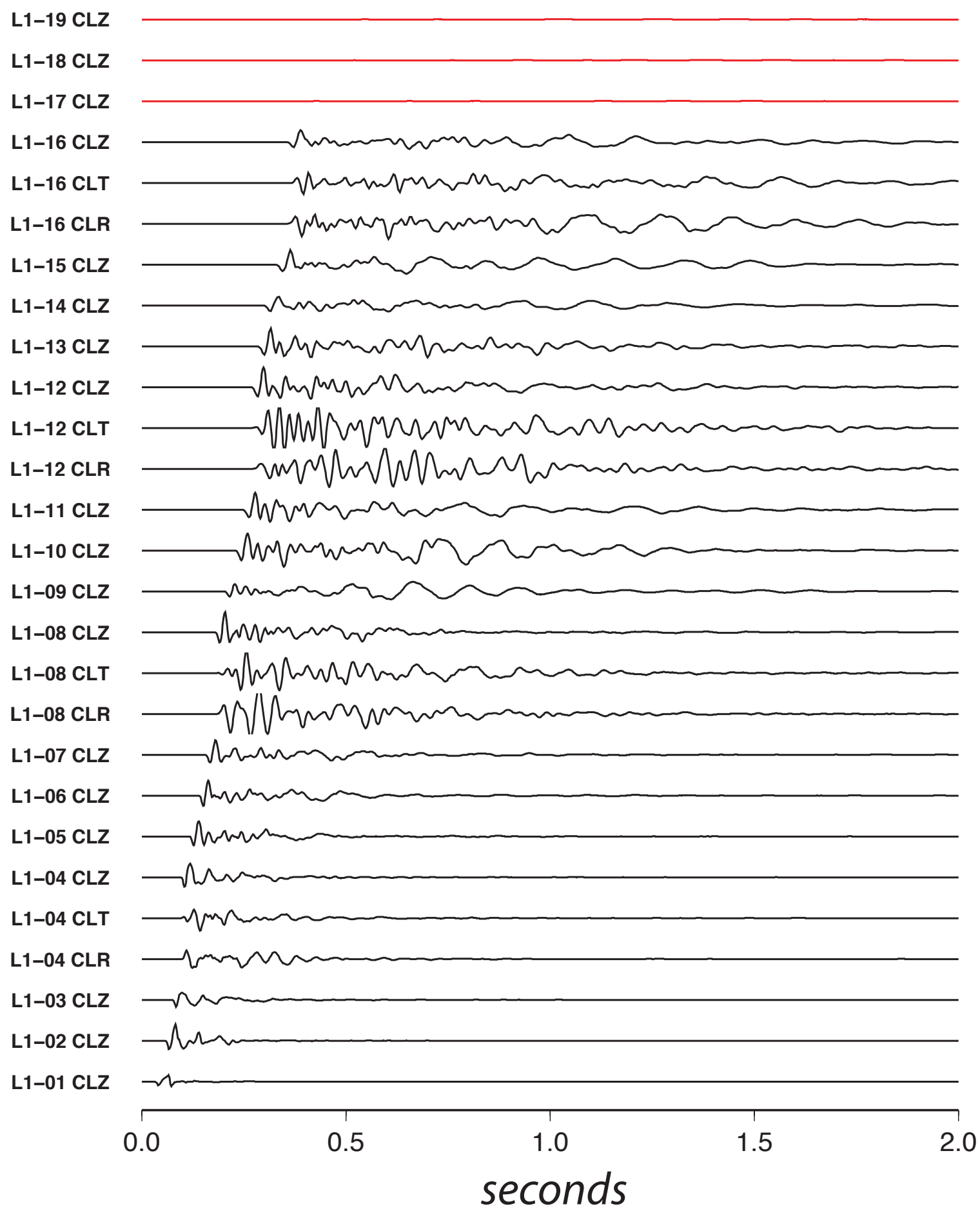

Figure 2. Line GS11D data 


\section{SPE3 L2 CL}

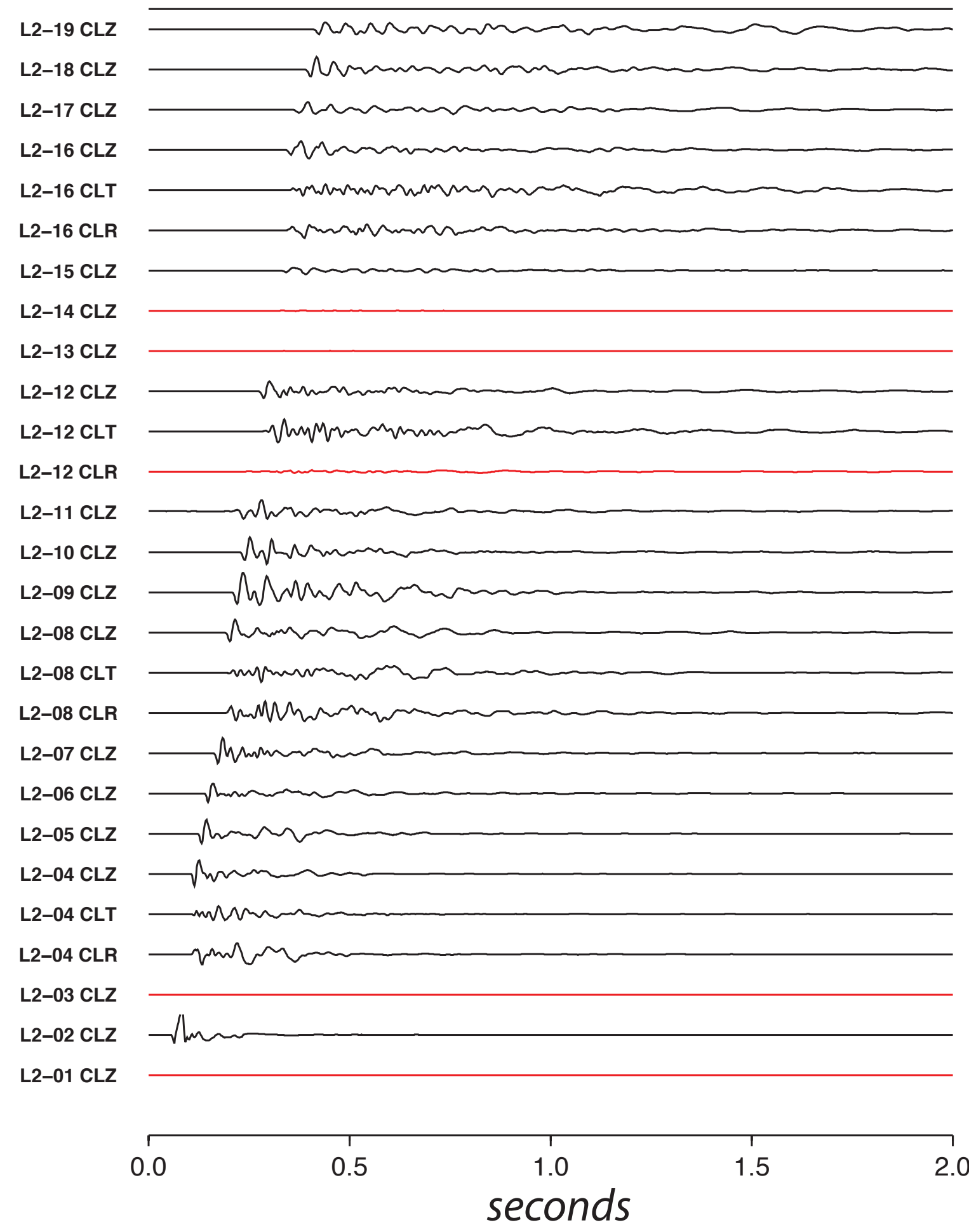

Figure 3. Line 2 GS11d data 


\section{SPE3 L3 CL}

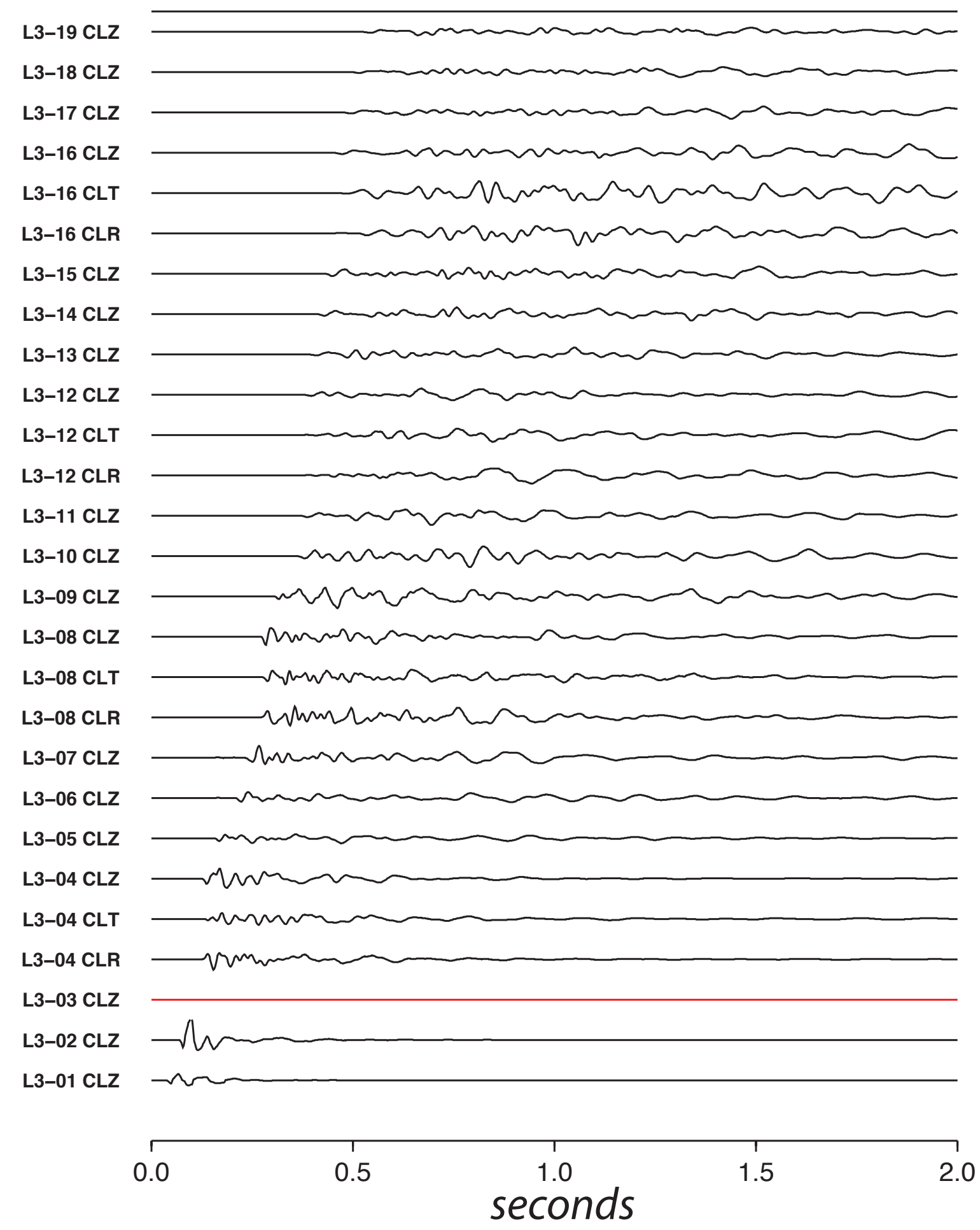

Figure 4. Line 3 GS11D data 


\section{SPE3 L4 CL}

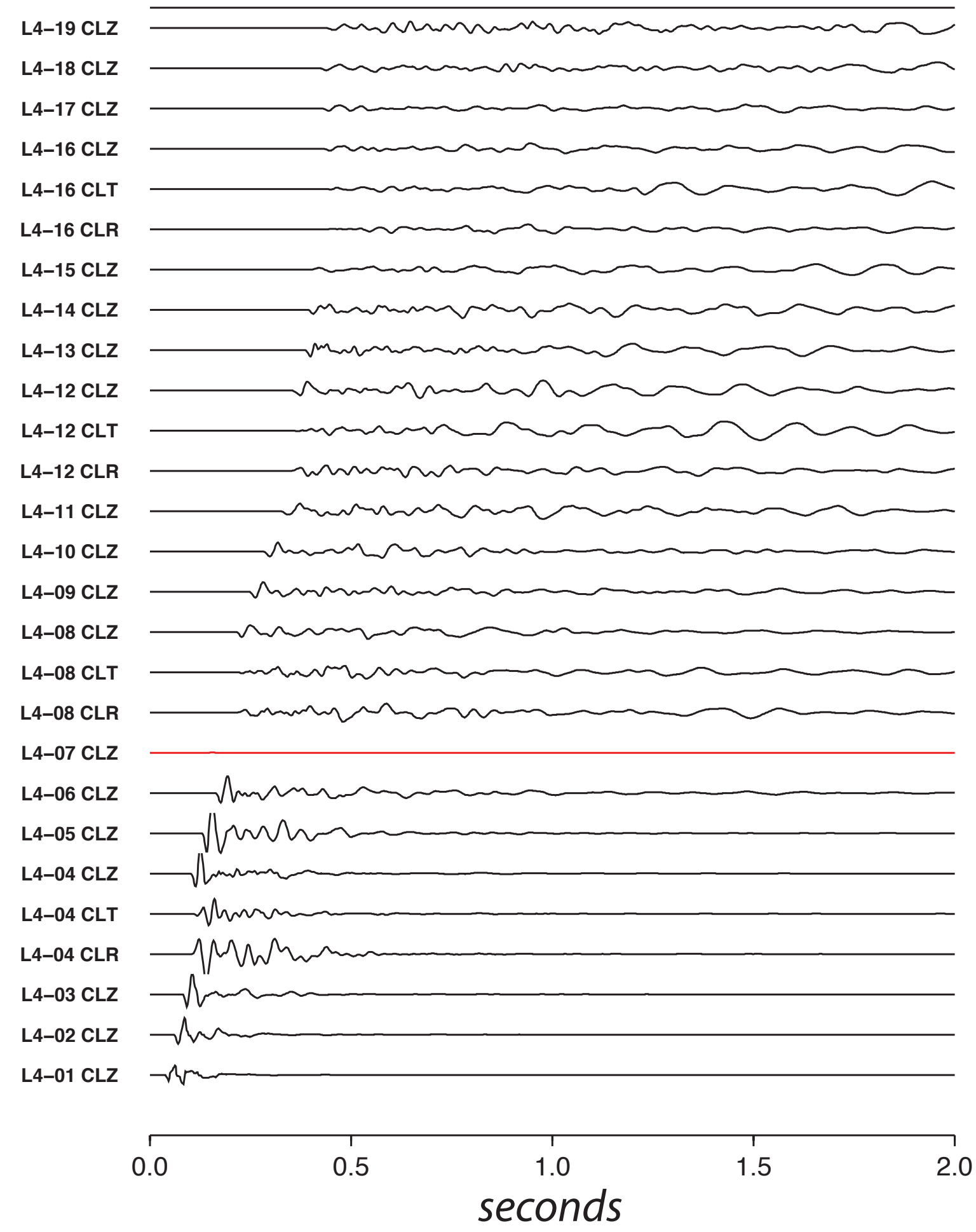

Figure 5. Line 4 GS11D data 


\section{SPE3 L5 CL}

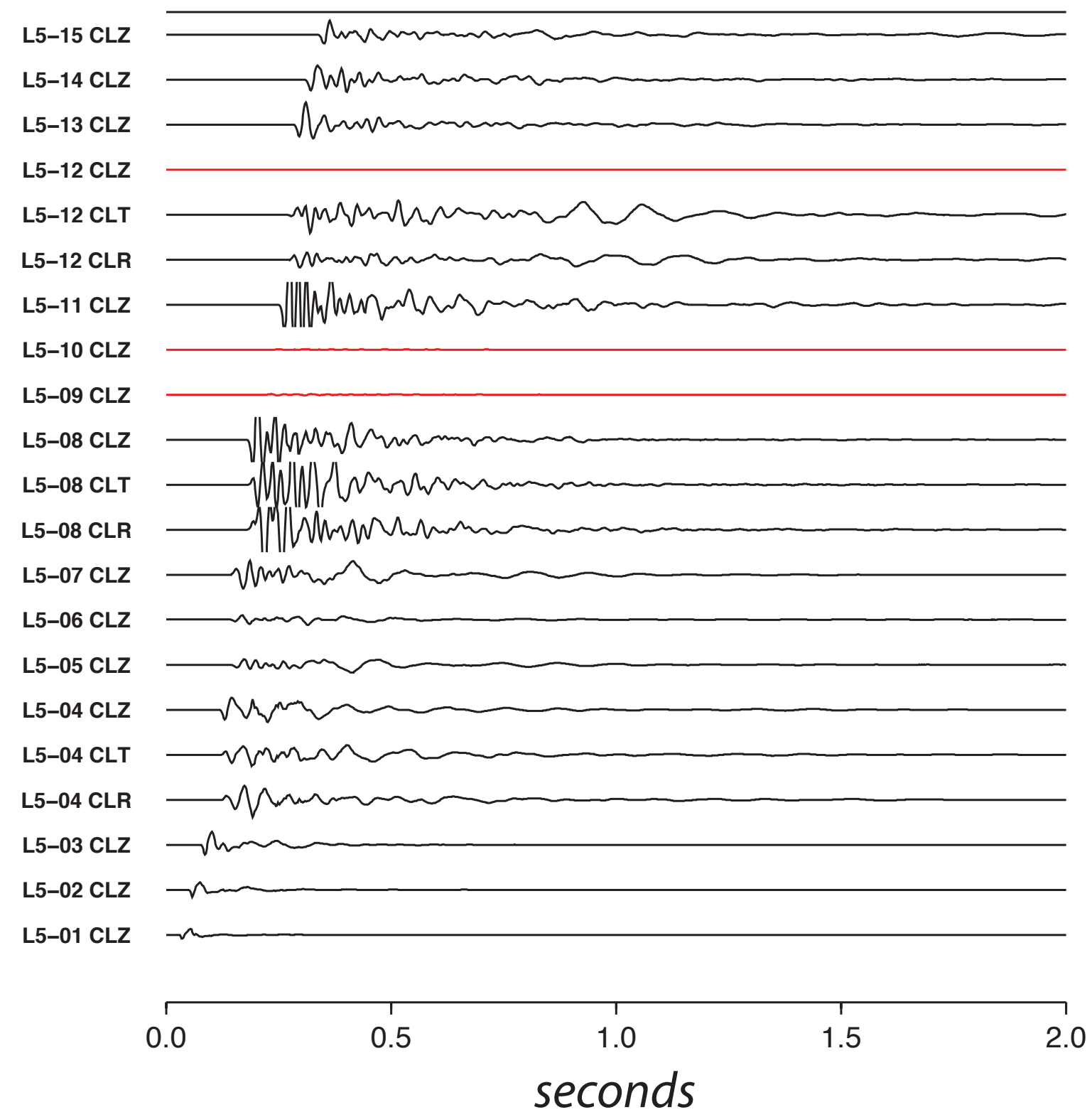

Figure 6. Line 5 GS11D 


\section{SPE3 CN}
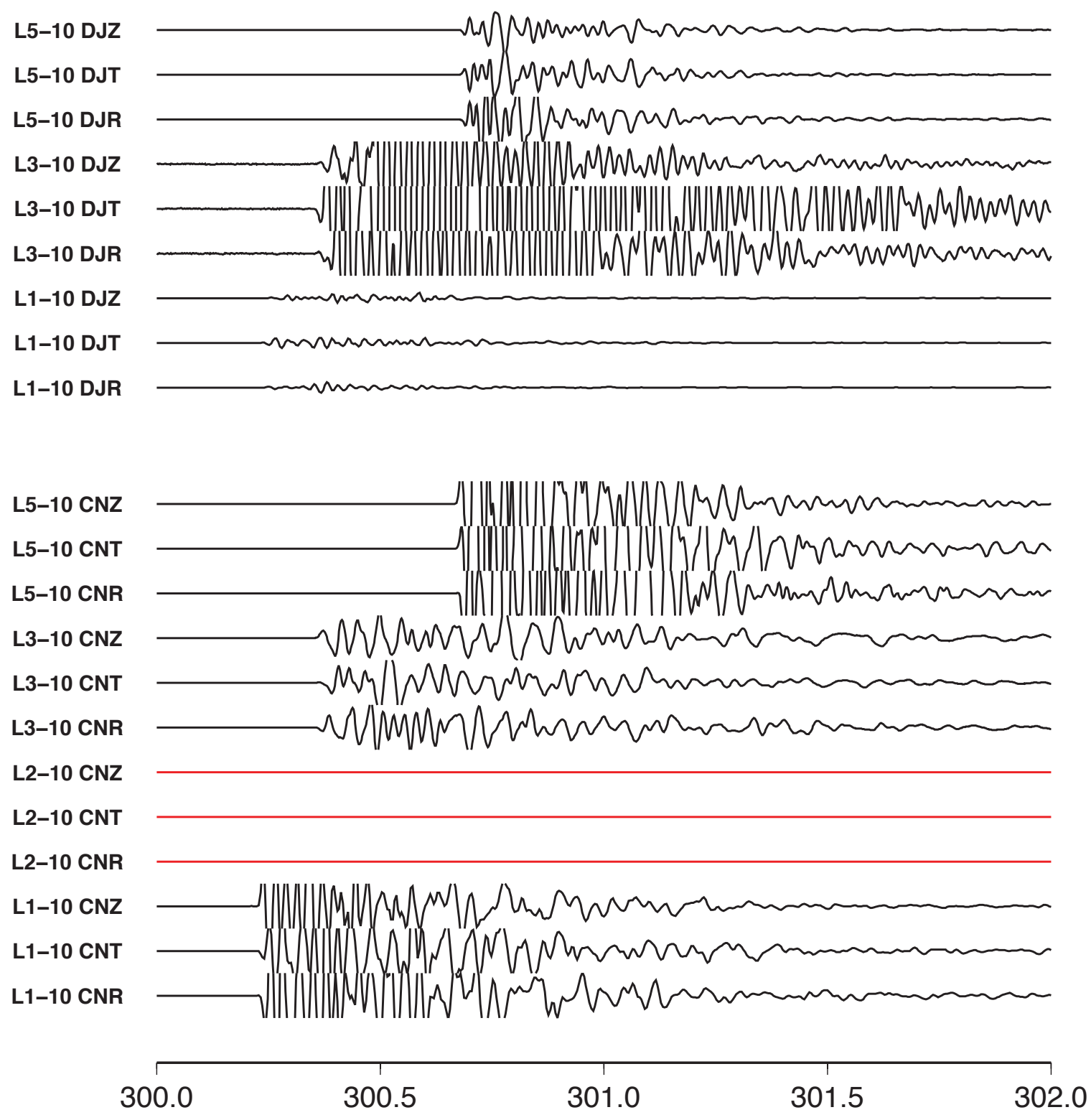

Figure 7. Episensor (CN) and rotational sensor (DJ) data. L1-10 and L5-10 are R1 rotationals; L3-10 is a different design. 


\section{SPE3 DH}

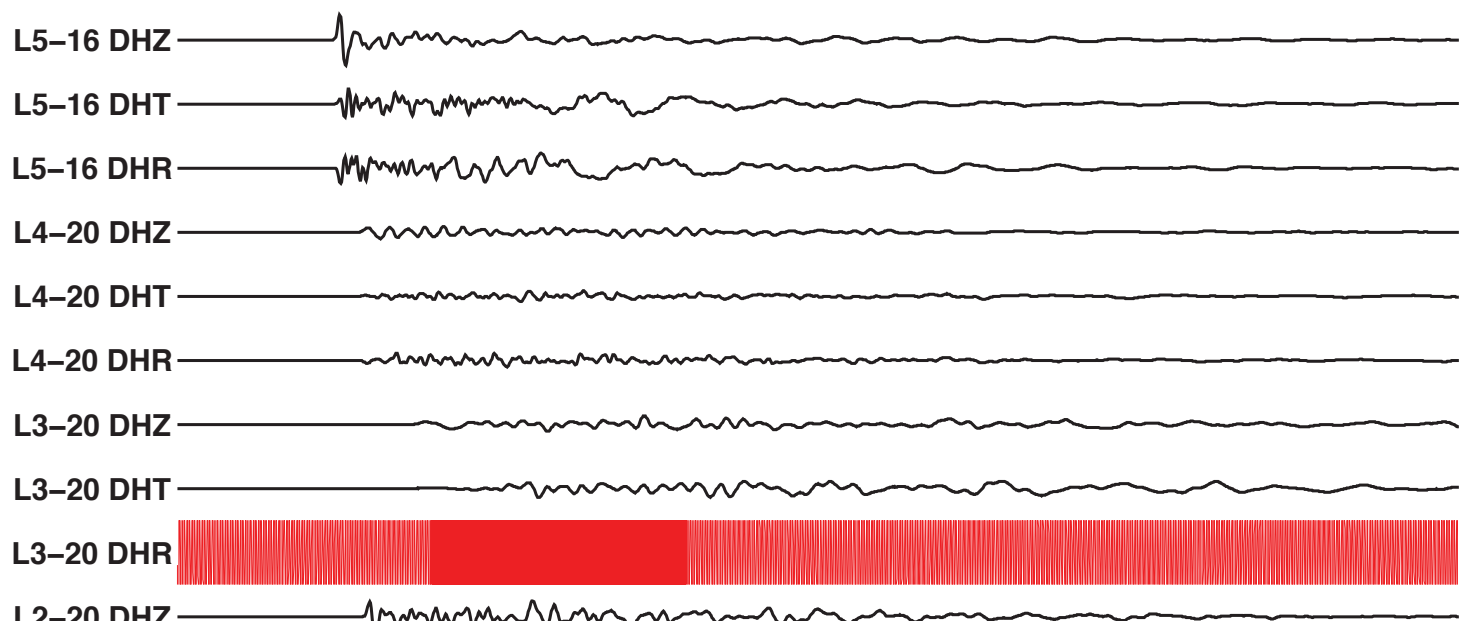

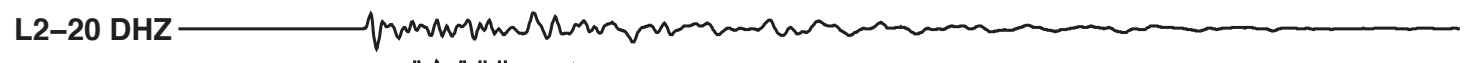

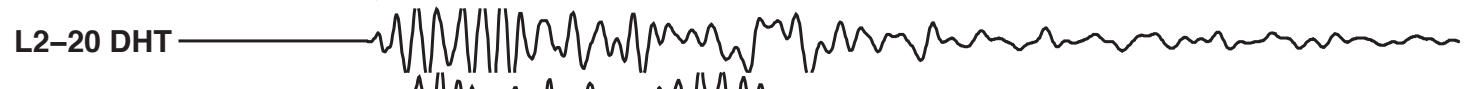

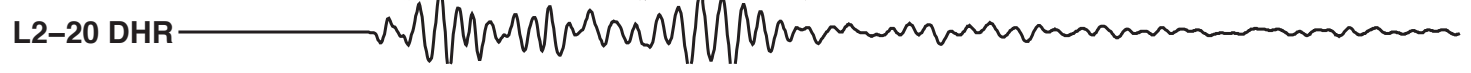

L1-20 DHZ

L1-20 DHT

L1-20 DHR

\begin{tabular}{lllllll}
\hline 300.0 & 300.5 & 301.0 & 301.5 & 302.0 & 302.5 & 303.0
\end{tabular}

Figure 8. Guralp CMG data. 


\section{SPE3 $\mathrm{CH}$}

L5-36 GHZ

L5-36 CHN

L5-36 CHE

L5-34 CHZ

L5-34 CHN

L5-34 CHE

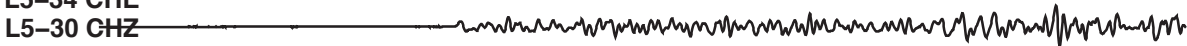

L5-30 CHN

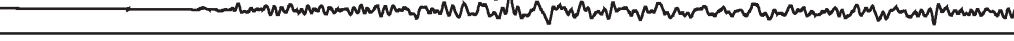

L5-26 CHz

L5-26 C+HN

L5-26 CHE CIE

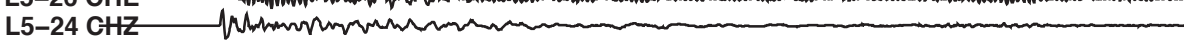

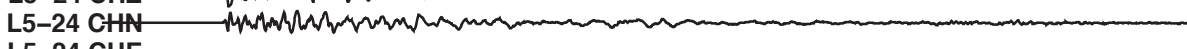

L5-24 CHE

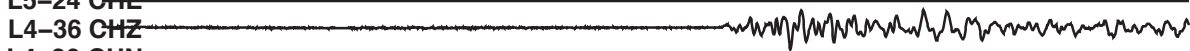

L4-36 CHN

L4-36 CHE

L4-34 CHZ
L4-34 CHN

L4-34 CHE

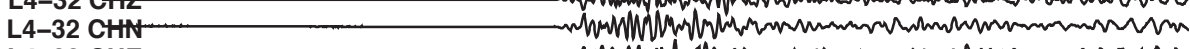

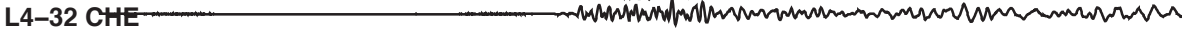

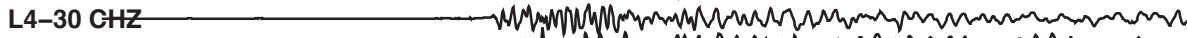

L4-30 CHN CHA

L4-30 CHE

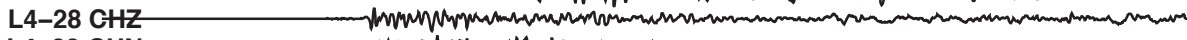

L4-28 CHN CANA

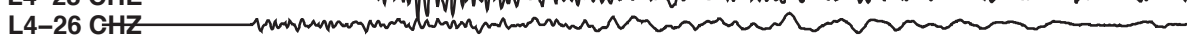

L4-26 CHN

L4-26 CHE

L4-23 CHZ W W

L4-23 CHE Min CHZ

L3-36 CHZ

L3-36 CHE

L3-34 G+2Z

L3-34 CHN CHE

L3-34 CHE CHZ

L3-32 C+IA

L3-32 CHE

L3-30 CHZ

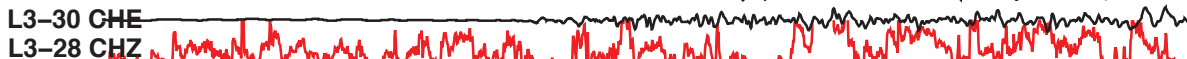

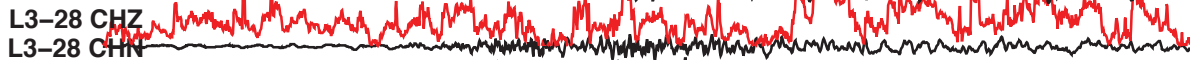

L3-28 CHE C.

L3-26 CHZ

L3-26 CHA

L3-26 CHE

L3-23 CHZ

L3-23 CHA

L3-23 CHE

\begin{tabular}{lllll}
\hline 300 & 302 & 304 & 306 & 308
\end{tabular}

Figure 9. Trillium $(\mathrm{CH})$ data 


\section{L1 CL}

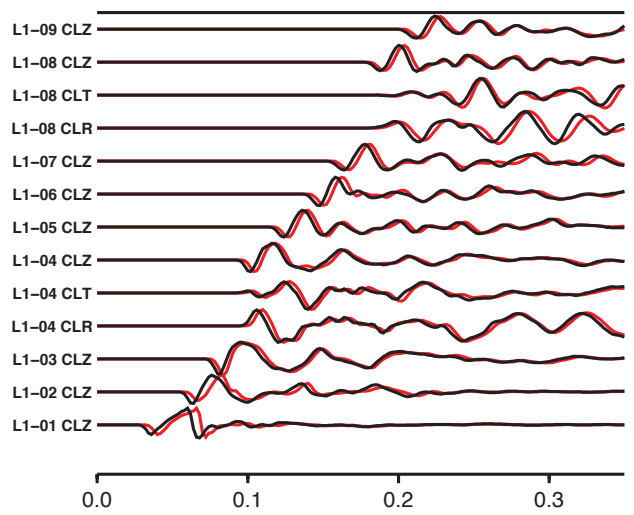

\section{L3 CL}

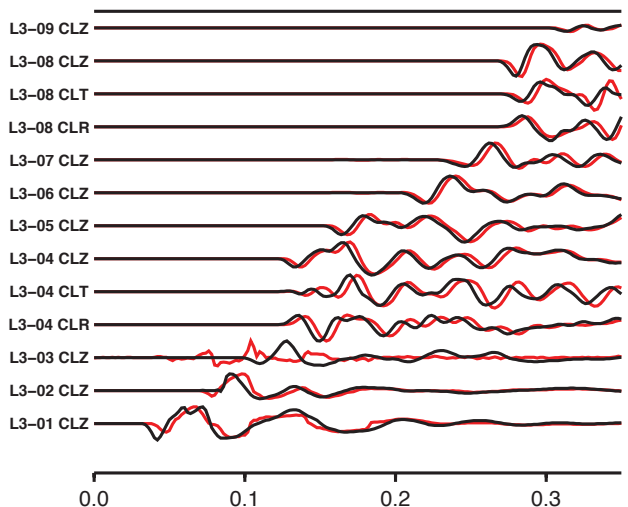

\section{L5 CL}

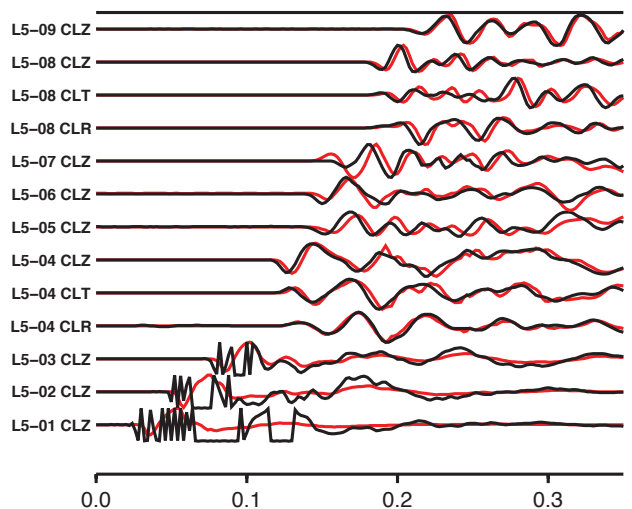

Figure 10. Comparision of SPE2 (black) and SPE3 (red) for the geophones. Note apparent delay of SPE3 with respect to SPE2. Traces are normalized.

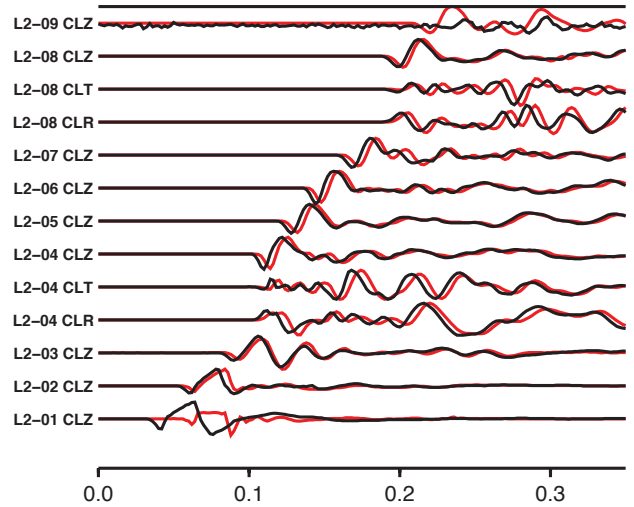

\section{L4 CL}

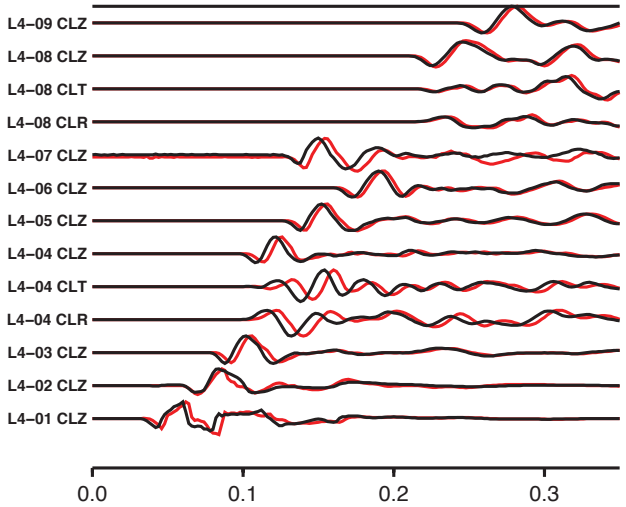

SPE2/SPE3 


\section{SPE3/SPE2 L1 geophones}

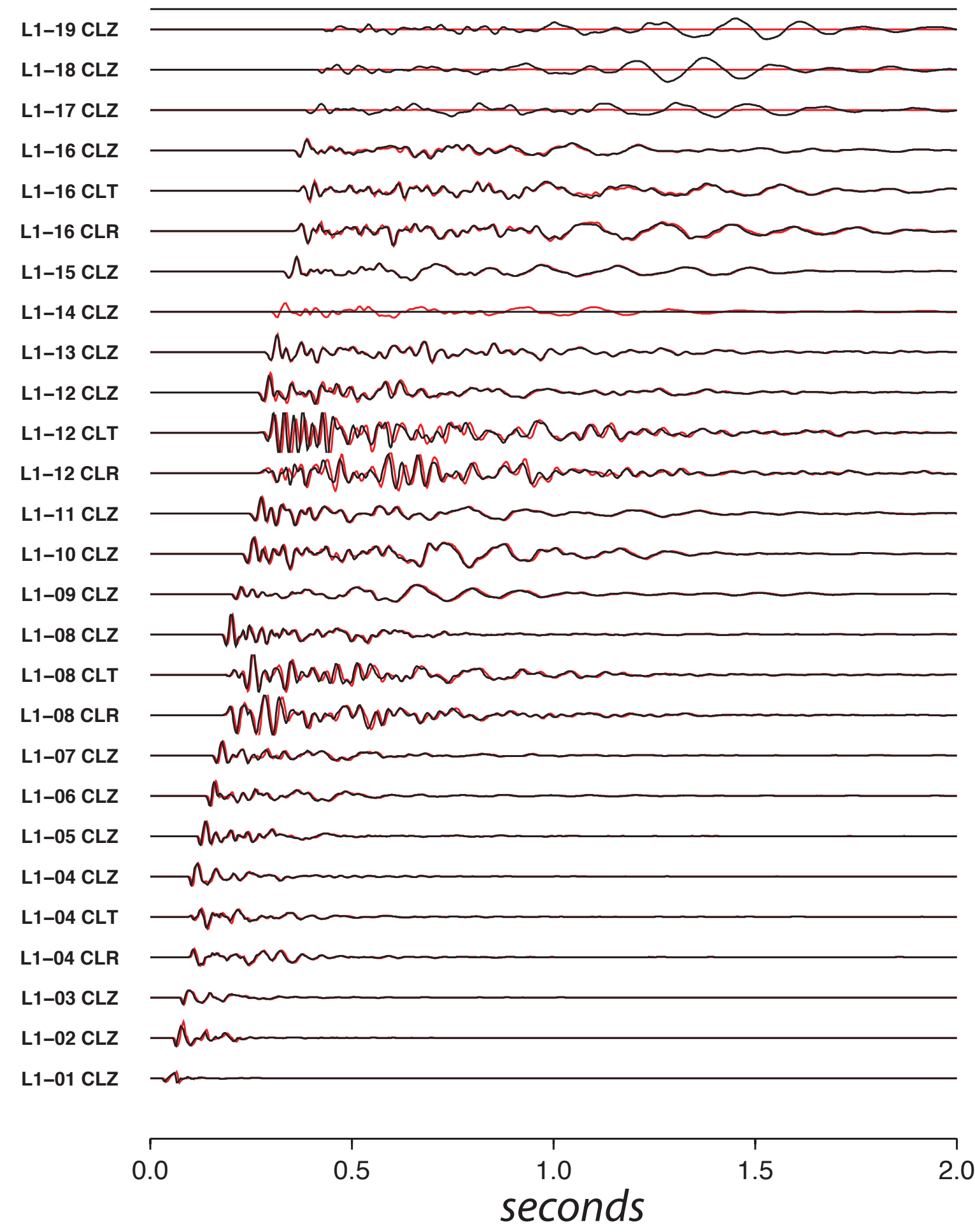

Figure 11. SPE2/SPE3 with relative scaling. 


\section{SPE3/SPE2 L2 geophones}

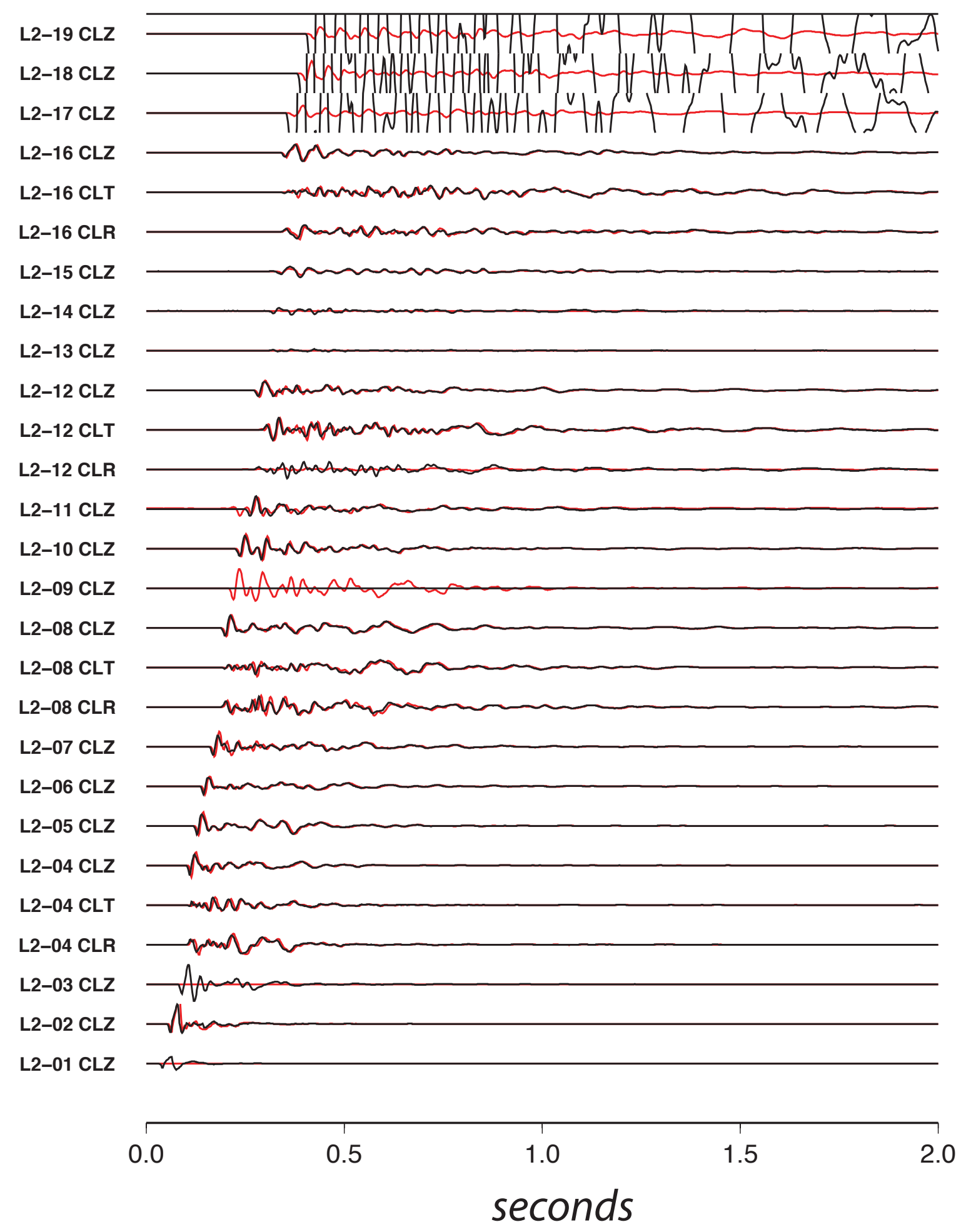

Figure 12. SPE2/SPE3 with relative scaling. 


\section{SPE3/SPE2 L4 geophones}

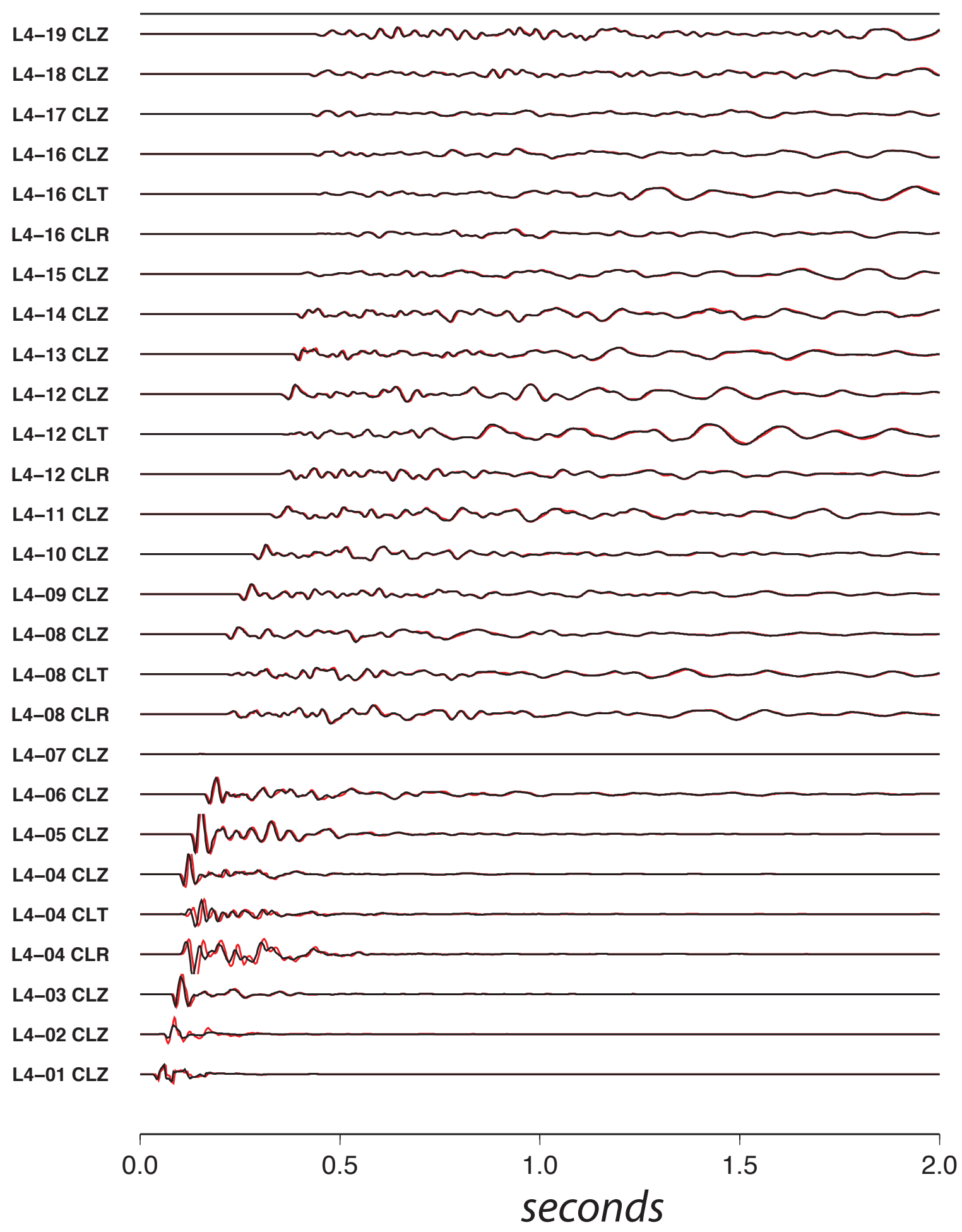

Figure 13. SPE2/SPE3 with relative scaling. 


\section{SPE3/SPE2 L5 geophones}

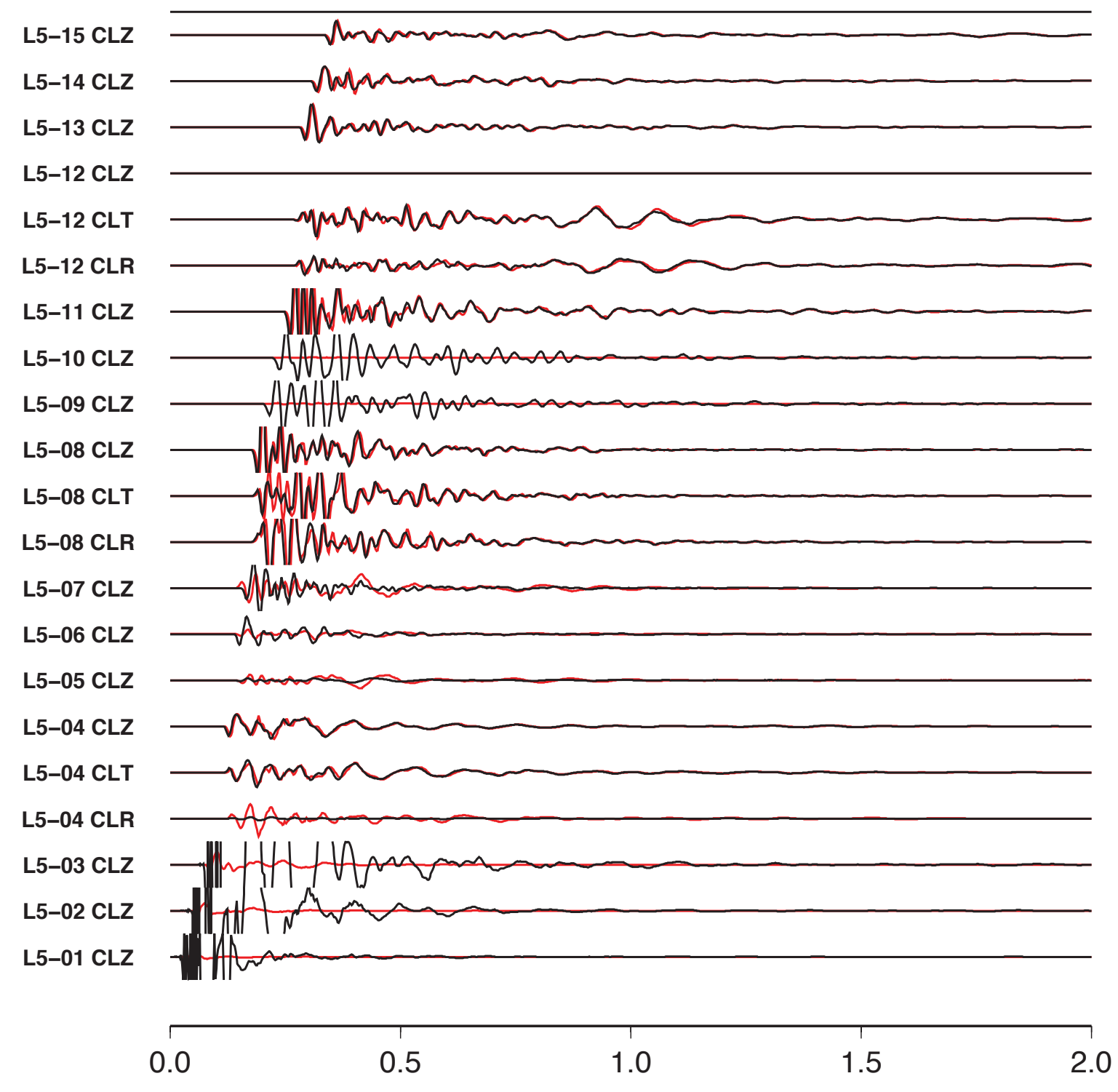

seconds

Figure 14. SPE2/SPE3 with relative scaling. 


\section{SPE3 geophone array}
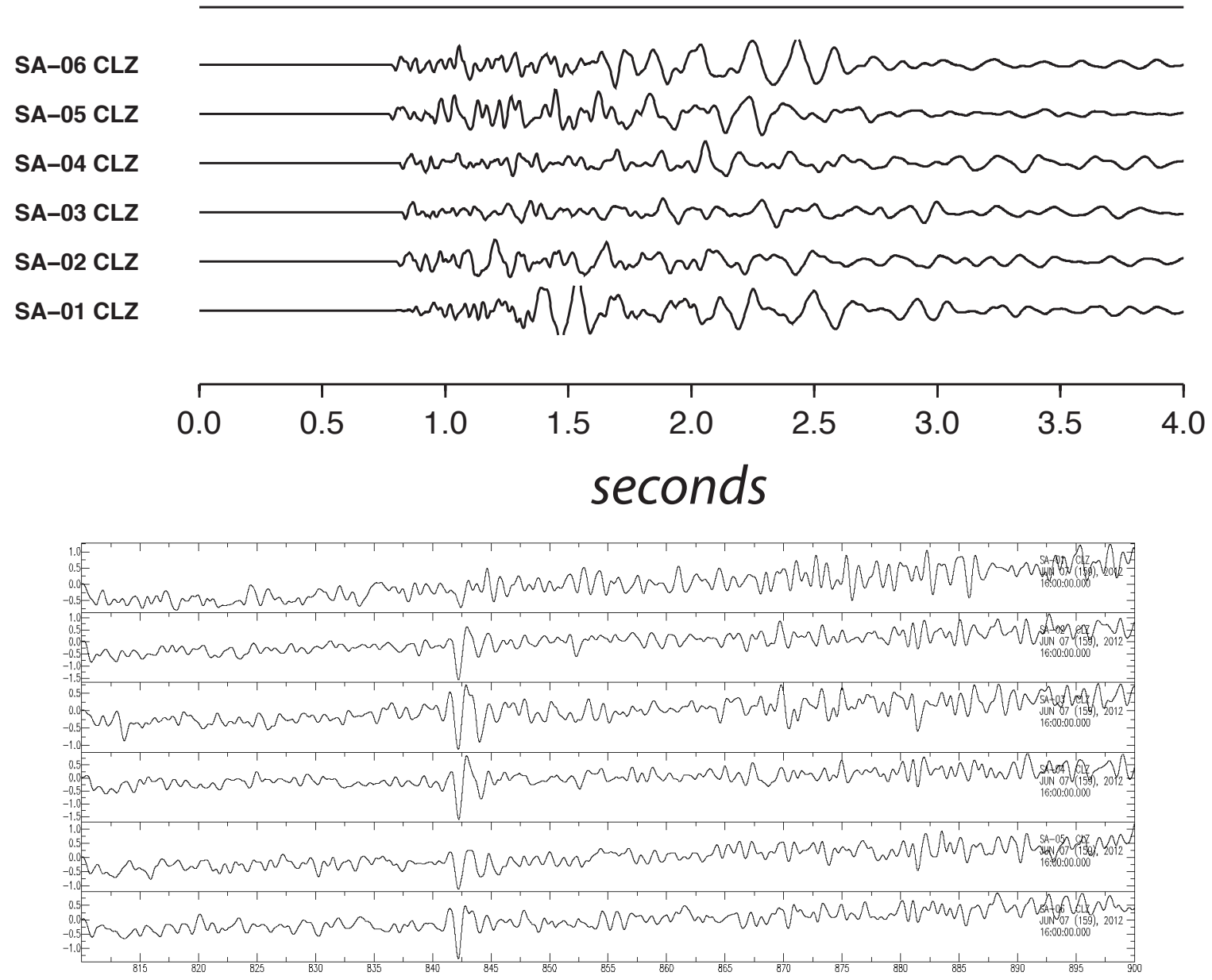

Figure 15. (top) SPE3 geophone array located SE of GZ. (bottom). Teleseismic recorded at small array. Note anomlaous appearance of top trace which is the center sensor indicating possible sensor/site problem.

This work performed under the auspices of the U.S. Department of Energy by Lawrence Livermore National Laboratory under Contract DE-AC52-07NA27344. 